\title{
Organizing the Activities of Management Companies on the Principles of Social Partnership
}

\author{
Alexandr Nikolaievich Gritcenko \\ Candidate of Economic Sciences, Branch of Russian State Social University \\ Kiev highway 5, Naro-Fominsky area, Moscow region, 143301, Russia \\ Email: a_gricenk083@list.ru
}

\section{Sergei Aleksandrovich Novosadov}

Candidate of Economic Sciences, Associate Professor

Branch of Russian State Social University

E-mail:ser-novosadov@yandex.ru

Maria Alekseevna Aseeva

Candidate of Economic Sciences, Associate Professor

Branch of Russian State Social University

E-mail: aseevamaria@mail.ru

\section{Olga Vladimirovna Gleba}

Candidate of Legal Sciences

Branch of Russian State Social University

E-mail: olga_gleba@mail.ru

Doi:10.5901/mjss.2015.v6n1s2p90

\section{Abstract}

The objective of the article is to create theoretical basis for the reconstruction of the in engineering and technical infrastructure objects. The modern society is permanently transformed and changed so that we have periodically to bid farewell to the methods and mechanisms of the command economy, as economy itself moves to a market development. With a change in economic development the rights and responsibilities of consumers are being changed. All this relates to such socially significant segment of the economy as engineering and technical infrastructure of the public life support system. The engineering and technical infrastructure is an essential life support and safety system, as well as a set of enterprises, services and households that serve the population of cities, towns and villages. In many settlements engineering and technical infrastructure maintain industrial enterprises as well, providing them with water, electric power, gas. It is offered to distinguish the economic efficiency of the service sector, characterized by the relation between the achieved results and the costs of different available resources, and the social effectiveness of service sector, which meets the public's needs in services.

Keywords: management companies, engineering and technical infrastructure, economic mechanism, economic methods and instruments, livelihood of citizens, municipal formation, modernization, social partnership.

\section{Introduction}

The need to improve existing mechanisms in the life support system of municipal formations while performing modernization and reforms in engineering and technical infrastructure (ETI) currently arises in Russia. All this can be achieved by introduction into effect of economic mechanism entailing economic methods and instruments, legal, regulatory and informational support.

Special attention shall be paid to the management efficiency of financial flows circulating both in system and in ETI.

Market relations dictate specific terms in this issue which is determined by transition to a full self-financing of the life support system, and move towards a full remuneration by citizens of services provided by ETI organizations and enterprises. It's important to take into account in this respect that the life support system itself is socially significant so that 
the contradictions implied in real sectors of national economy are most clearly demonstrated. These contradictions have revealed the shortcomings in reforms undertaken in the life support system, exacerbated the relations between state, municipal powers and private business.

ETI organizations and enterprises perform crucial function of citizen's life support and therefore are very significant not only for municipality formations but also for the country as a whole. Only effective and fast growing system, including its separate structural elements, can successfully implement the crucial for the country's population function. Unfortunately, at the moment this does not happen, and the situation in the system is clearly unfavorable. Under these conditions, feasibility of social projects initiated by state's authorities will increasingly be restricted due to ETI retardation and its destruction processes.

Obviously, only the reforms which are really for the benefit of people are of current importance. But the practical result of modernization and reforms is excessive, systematic, largely unjustified and groundless increasing of amounts of payment for life support services, inadequate to the level of quality. Adopted self-sufficiency policy with regard to the chronically unprofitable and deeply crisis system could not give any other result. The situation has worsened by the preservation of the previously existing archaic payment system based on conventionally established standards of consumption, with placing on the consumers the burden of paying the cost of production of such services, with the loss of resources in collapsing ETI highways and networks, which certainly will lead to systematical increase of payment burden on population.

Market principles and rules, taken in the wrong way, being suitable only in the sectors of the economy focused on profit-making, but little acceptable in such socially important areas as public life support, resulted in the formation of the above course. The main objective of system operation and the measure of effectiveness corresponding to it need to be directly associated with its main purpose, which is continuous maintenance of necessary conditions of comfortable and safe living and life support, i.e., based on the need to solve this major social problem.

\section{Method}

The major problem in implementing the existing concept of reforms in system of citizens life support is that being theoretically correct, it is not motivated by the interests of the participants, the municipal authorities, average users of services, as well as ETI companies, until recently, did not have either desire, or the ability to facilitate to market reforms in the system of public life support" (lakovlev, 2008).

Hence, the need to reconstruct the ETI objects appeared. The Federal Law of the Russian Federation dated June 21, 2005 No.115-FZ "On Concession Agreements in the RF" relegates to the reconstruction of ETI objects the measures on their rearrangement on the basis of introduction of new technologies, mechanization and automation of manufacture, modernization and replacement of out-of-date and worn-out equipment with new, more efficient equipment, on changes in technological or functional purpose of the concession facility or its separate parts, other measures for the improvement of concession facility's performance and operating characteristics (Federal Law of the Russian Federation [FLRF], 2005).

The principal purpose of the reforms would have been a significant improvement in the life support of citizens by improving the quality of service with ensuring affordable amount of payment for it (Tsarev, 2001, p. 206).

Thus, these purpose and criteria shall reflect both the social and commercial problems of system's functioning and development. This is why it was made the proposal to establish an operating organization, conducting business on social partnership principles (hereinafter the Organization). In the system of social partnership the interests of employees, as a rule, are represented by trade unions and interests of employers - by employers' associations.

In its so-called three-parties modification the third direct participant in the process of congruence of interests is a state, which at the same time acts as the guarantor of the adherence to the approved agreements. Congruence of interests is achieved through the negotiation process, in which the parties agree on the labour conditions and remuneration of it, on social security for employees and their role in the enterprise activity (Husov \& Tolkunova, 2006, p. 182). The Labour Code clearly indicates the difference between the parties, participants, forms and bodies of social partnership, determines its types and the concepts of employees' and employers' representatives, enshrines the principles of social partnership (Labour Code of the Russian Federation [LCRF], 2005, art. 25-35).

This Organization shall bear the status of the management company, and manage the operation and maintenance of housing/non-housing stock of the municipal formation. The functions and powers of its members shall be allocated on the basis of corporate and trust agreements concluded by them.

The members of the Organization, together with the municipal authorities develop the basic environment of legal, economic and business (market) relations with a glance to optimize the resource consumption.

At the input the capital and current assets come to the balance sheet of the Organization. Cash flow between the 
members inside the model is carried out without taxation (as within one process cycle). But in the end fiscal performance will be higher than in the traditional open cycles as the speed of commodity-money circulation of goods and services at the output increases many times.

The Members of the Organization are the economic entities operating on the basis of economic independence and responsibility. In vesting them municipal property the mechanisms of socially justified privatization and concession will be directly involved. The equal competitive conditions should be created for all enterprises in the market of life support services.

Therefore, the tasks of the municipal authorities will be the following:

1) provision of the budget funds in order to finance the particularly important projects in the framework of the reforms in the life support system and ETI on a return or a non-return basis;

2) provision of guarantees on borrowings from various organizations, as well as other forms of financial support;

3) co-financing of the program of targeted social protection for expenses on housing and community services.

At the local government level in order to test the Organization's activity the following steps are envisaged:

1) development of new uses of limits on the maintained housing stock transferred to municipal ownership;

2) provision of the local budget funds for the modernization of the fixed assets complex on repayable and nonrepayable basis;

3) provision of guarantees and other forms of raising funds support by the Organization;

4) testing and development of market mechanisms in order to raise private investors' funds for modernization of ETI facilities and technical reequipment of services.

The Organization performs its functions in cooperation with divisions of the municipality formation, enterprises and participants of the model. Pursuant to the concession agreement and agreement on transfer of municipal property in trust management, the Organization is transferred such securities: warehouse warrants, bills, certificates of pledge and mortgage certificates, debt securities (if any). The liabilities on organization of securities management, the insurance of economic activities and business risks fall on the authorized or newly created specialized credit and financial institution, which must bear municipal status.

The municipal financial and credit institution (hereinafter MFCl) as a participant of the Organization is the main financial body that plays a key role in augmentation of domestic investment capital of the Organization and capital of its members by way of monetary and credit operations. In the structure of the MFCl Organization the functions of financial and credit institution, financial settlement center and universal information unit shall be combined.

In the framework of MFCl common information space three types of centers are considered.

I. Centre for community affairs, which incorporates:

1) the department of housing subsidies that receives public on all matters of processing of housing subsidies (decreasing the need to collect a variety of certificates);

2) the process control room, which receives public on the matters of payment for life support services (including the provision of benefits, recalculation of accounts in case of poor delivery of services, of partial payment for certain services, issuance of duplicate billing invoices, personal receipt of billing invoice, noncash write-offs);

3) the billing office, raising public funds as payment for public services, including payments for execution of documents and passport registration.

II. Analytical information and computing centre, which:

1) calculate the cost of services, the amount of benefits and subsidies on the basis of unified payment document, generates billing invoices for the public;

2) amends the settlement documents between the public and contractors when the tariffs, amounts of benefits and subsidies change, and recalculates accounts in case of poor delivery of the life support services;

3) keeps book records of contractors and administration;

4) predicts financial requirements to cover housing subsidies.

III. Process Center, performing the following operations:

1) maintenance of the accounts of participants in the model and data management (in particular, keeping records of the funds received from the citizens in respect of payments for the operation, maintenance and repair of residential housing stock, citizens' and lessees' payments for life support services);

2) income accounting and distribution of funds for rendering targeted social assistance;

3) receipts accounting and distribution of citizen's payoffs between contractors for services provided;

4) authorization (permits or denies) in real time (on the grounds) of the payment transaction according to the 
established rules based on the available funds deposited in accounts (personalized account of a citizen, owned, municipal, subsidized and other accounts);

5) issue of relevant payment orders on the accrual of funds for subsidized and other municipal accounts;

6) provision of a detailed accounting by personalized accounts, accounting of banking operations;

7) administration of subsidized, municipal and other accounts;

8) remittance of budget funds in accordance with the data obtained from the Cash Settlement Centre to the accounts of the enterprises that provide services;

9) issue of payment cards, which may be used for execution of payments;

10) implementation of temporary crediting of subsidized accounts.

Along with it the task of creating additional jobs and formation of cooperative units in life support system, at the ETI facilities, and in related areas shall be solved. In addition, the local administrations are exempt from business, manufacturing and service functions which, being unusual for them, switch to a professional basis under the jurisdiction of the model and its participants.

As a result of its activities the Organization shall come to the following:

1) improving the sustainability of the system of municipality life support, mainly using the citizen's funds, attracted by the Organization as a loan;

2) enhanced comfort and safety of the living conditions of the citizens;

3) the reliability of the engineering systems of municipality life support;

4) improving the efficiency and quality of the public life support services;

5) the social protection in payment services (in conjunction with measures of state support);

6) reduction of the tariff burden on the population with increasing contribution of the private sector in the management of assets.

For implementation of the above recommendations, we propose a new approach to evolve relationships between the links of the economic mechanism of public life support and conceptual model of management. Management of these relationships is presented in Figure 1. In terms of improving tariff policy, preparation of methodology documentation on procedures for tariff regulation must be held, including the development of the principles of social and preferential tariffs.

In the process of idea implementation, development of socially oriented market relations is anticipated based on restructuring of forms of ownership and management of basic as well as external servicing and supplying enterprises and organizations.

Special development motive of this system is given by the conversion of ETI enterprises activities to an entrepreneurial basis in collaboration with the municipal government, which contributes to the rapid development of small business, competition in the provision of services, hence, resulted in improvement of their quality, that stipulates investment attractiveness of the new projects and the renovation of old ETI systems for the banks and big business. The outcome of changes is increased consumption, quality and services utility as the main goal of this model.

This concept of ETI management exercised by operational organization which is established on the principles of social partnership, and its infrastructure member companies and organizations reveals the main directions and methodological approaches of the proposed activities.

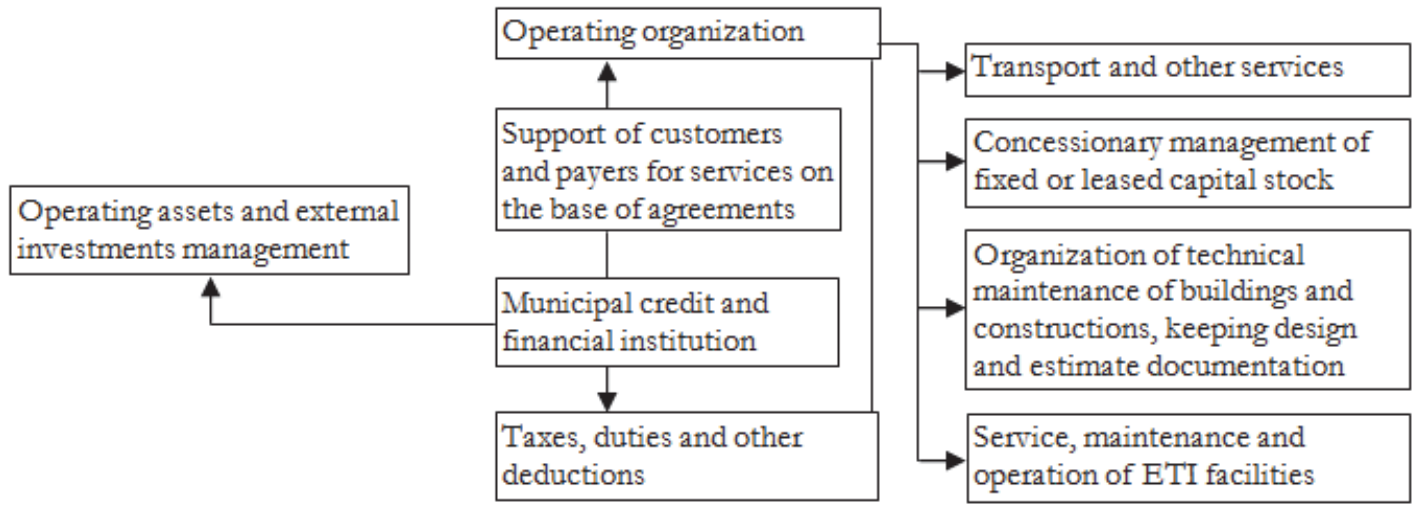

Figure 1: Conceptual model of relationship management in the system of public life support with the participation of Operating organization founded on the principles of social partnership 
Specific recommendations developed on its basis focus on the formation of a new quality of service, its socially considered pricing, thereby promoting technological modernization of production, upgrade of equipment, communication systems, and most importantly - improvement of safety and comfort of the living standards of Russians.

The developing relationships, being formed on the basis of the proposed management model, may appear to be a source of revival of the phenomenon of "social partnership" in terms of which, through the realization of common interests, trusting relationships will arise and the responsibility of parties that are the bodies of government and municipal management, entrepreneurs and residents of municipal formations according to the program "Resident participation" will heighten. The main result should be a mutual desire of all the process actors to jointly achieve civilized results that meet the vital interests of the state, as well as the interests of the individual. In such circumstances, it is possible to find a civilized solution to the problem of partial compensation to the indigents of the costs for services and the expenditures for maintenance and repair of ETI using economic methods.

In summary, the following assumption can be made:

1) the "social partnership" is a term used in the economic literature, was not applied to such area as public life support system;

2) the social orientation of the partnership focuses on creating the best, favourable, namely the normal living conditions for the citizens of the Russian Federation in multifamily house;

3) the new model of operating organization can be the basis of the reforms in the system of life support and enhance the effectiveness of the economic mechanism as the system and its individual elements.

The primary objective and performance criteria of organization founded on the principles of social partnership are to provide favorable living conditions and livelihood for people pursuant to applicable standards. Reinforcement of this target can be found in the current legislation of the Russian Federation on local government, which prescribes to satisfy the basic requirements of people in the areas falling within the jurisdiction of municipality formations at an equal or higher level comparing with the social standards (Cherniak, 2008, p. 45).

In the development of market relations this target orientation must be maintained and increasingly enhanced. This tendency appears from the modern marketing theory, which was introduced in developed countries in view of its immediate, practical needs. The objective of the firms in a competitive environment, in accordance with the fundamental marketing principles, is to satisfy the needs and requirements of people.

With respect to life support system, initially focused according to its intended purpose on satisfaction of quite definite variety of people's needs and demands, the special attention should be paid to caring for consumers. Various scientists studying ETI problems define operating efficiency of enterprises of engineering infrastructure organizations in a different way.

The effectiveness of life support services is characterized by the relation between the achieved results and different available resources that were spent. In our view, the effectiveness of providing such services should be determined by achievement of the maximum results for the sake of public with minimum amounts of production means and manpower. But this doesn't mean that the effectiveness should be bounded only to the expanding of the range of services and costs reducing. In determining the effectiveness the important role belongs to the social impact, because, first of all, even a significant effect of resource management is not yet an increase of production efficiency, if it is accompanied by deterioration of working conditions; secondly, the increase in the amount of services rendered and works performed as a result of more efficient use of resources should match the needs. Otherwise, the society will suffer dead expenses rather than increase of the ETI efficiency.

Hence, if we consider the worthwhile results of the activity of life support organizations and enterprises, such expected significant results should meet all the needs of society - material, spiritual and environmental.

Studying the problem of methodological bases of analysis of ETI life support systems and elements in national economic science, we can mention that most economists increase focus on the following aspects or criteria of effectiveness analysis: 1) the dynamics in specific cost changes for delivery of life support services; 2) financing of ETI organizations services; 3 ) changes in accounts receivable and payable, as well as losses of enterprises in the current year, in absolute and relative terms; 4) analysis of tariffs and setting of service prices; 5) the proportion of the citizen's payoffs in payments for life support services; 6 ) the number of families - the recipients of grants and the amount of budget funds allocated for their provision; 7) the number of persons - the recipients of benefits and the amount of budget funds allocated for their provision from energy saving; 8) the ratio between the number of the current year and the previous year accidents; 9) the level of ETI system deterioration; 10) the volume of fully repaired and renovated housing stock in relation to the previous year, and others.

These indicators can be reasonably considered as criteria of operational effect both of life support systems and ETI. They allow us to give a comprehensive assessment and draw objective conclusions. However, it is evident that there 
is a lack of such indicators that one way or another would reflect the social aspects of the issue.

Therefore, the authors consider it necessary to supplement the study with the list of the following indicators: 1) the degree of public satisfaction with the services (the number of complaints and appeals from the citizens, the possibility of a free exercise of housing rights and freedoms, etc.); 2) indicators of entrepreneurial activity in this field; 3 ) the level of investment activity; 4) ensuring compliance with state social standards of service in the field of life support; 5) reduction of costs for the provision of public services in comparable conditions; 6 ) reduction in consumption of fuel and energy resources - resource saving process.

It is offered to distinguish: 1) the economic efficiency of the service sector - characterized by the relation between the achieved results and the costs of different available resources; 2) the social effectiveness of services sector - full meeting of the public's needs in services.

\section{Results}

Thus, the life support services shall not only be economical - they must be optimal.

In conclusion it would be appropriate to note that the principle of profitability shall not only be the main principle and purpose of the activity of ETI enterprises. Profit-making is acceptable, but not in circumstances of a low living standard of bulk of the population, poor technical equipment and worn-out state of infrastructure, default in payment for services by users and their low quality, when social rather than economic efficiency comes in the forefront. Here profitability is unlikely to serve as indicator of the operating effect of the ETI domestic enterprise. In these conditions, obviously, in the near future the quality of services provided for consumers on the basis of reasonable prices shall serve as an indicator of social performance in this area. At the same time this conceptual criterion should retain its value in Russia even while eliminating most of the reasons that hinder the development of life support system for the residents of human settlements.

\section{References:}

Cherniak, V. Z. (2008). Economics of Construction and Public Utilities. Moscow: YUNITY.

Federal Law of the Russian Federation \# 115-FZ "On Concession Agreements in the Russian Federation" dated 21.06.2005. Husov, K. N., \& Tolkunova, V. N. (2006). Employment law in Russia. Moscow: Yurist.

lakovlev, B. M. (2008). On the evaluation of the effectiveness of housing and utility services. Proceeding of the conference. Labour Code of the Russian Federation \# 197-FZ dated December 30, 2001.

Tsarev, I. G. (2001). Reforming housing and utility services. ECO. Economy and organization of industrial production, 5, 53-67. 